\title{
Eoiropial Different laws, same principles: mental health and incapacity legislation across the UK
}

\section{Donald Lyons}

Donald Lyons is an old age psychiatrist with a long-standing interest in mental health and incapacity law. He has been Director of Scotland's Mental Welfare Commission since 2003. The Commission monitors the operation of mental health legislation in Scotland and acts generally to safeguard the rights and welfare of all people with a mental disorder. Correspondence Dr Donald Lyons, Director, Mental Welfare Commission for Scotland, Thistle House, 91 Haymarket Terrace, Edinburgh EH12 5HE, UK. Email: Donald.lyons@mwcscot.org.uk

\begin{abstract}
SUMMARY
England and Wales, Scotland and Northern Ireland are all at different stages in developing their mental health legislation. All jurisdictions have encountered problems in interpretation and operation of the various acts. As an introduction to a series of articles to appear in Advances on mental health and incapacity law, this editorial offers a commentary on some of the critical issues and suggests some key principles that everyone should follow in order to provide care and treatment that accords with best legal and ethical practice.
\end{abstract}

\section{DECLARATION OF INTEREST}

None.

Readers of Advances will find a series of articles on mental health and incapacity legislation over coming months, beginning with Branton $\&$ Brookes in this issue (pp. 161-167). It seems timely to take stock of relevant legislation across different parts of the UK (Box 1) to see the similarities, differences and challenges to psychiatrists. England and Wales have experienced the implementation of the Mental Capacity Act 2005 and its subsequent Deprivation of Liberty Safeguards (Ministry of Justice 2008)

BOX 1 UK legislation online

England and Wales

- Mental Capacity Act 2005: www.opsi.gov.uk/acts/acts2005/ukpga_20050009_en_1

- Deprivation of Liberty Safeguards: www.dh.gov.uk/en/SocialCare/Deliveringadultsocial care/MentalCapacity/MentalCapacityActDeprivationofLibertySafeguards/DH_082420

- The 2007 Amendments to the Mental Health Act 1983: www.opsi.gov.uk/acts/acts2007/ ukpga_20070012_en_1

Scotland

- Adults with Incapacity (Scotland) Act 2000: www.opsi.gov.uk/legislation/scotland/ acts2000/asp_20000004_en_1

- Mental Health (Care and Treatment) (Scotland) Act 2003: www.uk-legislation.hmso.gov.uk/ legislation/scotland/acts2003/asp_20030013_en_1

Northern Ireland

- Bamford Review of Mental Health and Learning Disability: www.rmhldni.gov.uk and of the 2007 amendments to the Mental Health Act 1983. In Scotland, the Adults with Incapacity (Scotland) Act 2000 was followed by the Mental Health (Care and Treatment) (Scotland) Act 2003. The former has already undergone amendment, the latter will soon. Northern Ireland is, at the time of writing, poised to introduce a Bill based on the Bamford Review of Mental Health and Learning Disability (Northern Ireland), which was published in 2007. This is intended to be a single Bill covering incapacity and compulsory mental healthcare and treatment.

If legislating for incapacity and mental ill health were easy then we would not have so many different laws across the UK. Internationally, legislation and practice vary greatly. Rates of compulsory treatment differ between countries (Salize 2004) and also within countries. In Scotland, rates of detention are twice as high in Tayside as in Lanarkshire, despite similar demographics in their populations (Mental Welfare Commission for Scotland 2009).

What factors determine whether people are treated under compulsory powers? Criteria for compulsion obviously have some impact but do not explain all the differences. Availability of community supports and of hospital places will explain some regional variations. Psychiatrists have individual attitudes and practices. We probably vary in our views on when compulsion is appropriate, when informal persuasion is sufficient and when to allow people to make their own decisions.

In the series of articles to be published in Advances over the next few issues, there are helpful analyses of some of the thornier parts of mental health and incapacity law. I have picked out some for comment here. They are: definition of mental disorder, capacity as a fundamental concept, the right to refuse treatment and community orders.

\section{Definition of mental disorder}

Definitions of mental disorder show similarities and differences. Across jurisdictions, the general 
approach is to have a wide definition of mental disorder and then to narrow down the subgroup that can be compelled to have compulsory treatment. This involves applying tests of risk (all jurisdictions), treatability (all with some wording differences), capacity (in some form in Scotland and almost certainly Northern Ireland) and necessity. In this issue, Branton $\&$ Brookes (2010) describe the amendments to definitions and criteria for England and Wales and assess their likely impact.

Personality disorder is still a difficult issue and one where there are different views among psychiatrists. The approach in England and Wales has been to qualify the mental disorder criterion by applying the test of "nature or degree that requires detention in hospital'. Sen $\&$ Irons (2010) argue that this will not result in more people with personality disorder being given compulsory treatment than before. Availability of treatment (in its broadest sense) will result in differing clinical opinions. Emphasis must be on care and treatment, not merely custody. The test of decision-making ability will probably exclude from civil compulsory orders many people in Scotland with personality disorder but this test does not apply to mentally disordered offenders. Northern Ireland will need to find a way to finesse their law as, if incapacity is a criterion for compulsion, there is a risk that some people with personality disorder who have committed an offence may miss out on hospital treatment that will help them.

\section{Capacity as a fundamental concept}

Capacity in relation to treatment decisions is likely to be fundamental in Northern Ireland. At present, it is not a test in England and Wales for the Mental Health Act but the test in the Mental Capacity Act seems appropriate for both pieces of legislation. Scotland's test of 'significantly impaired decisionmaking ability' (SIDMA) under its Mental Health (Care and Treatment) Act is not the same as the test for 'incapacity' under its Adults with Incapacity Act. If we focus on civil compulsory treatment, should we subject people to compulsion if they have capacity to make their own decisions about whether or not to accept treatment? I argue that we should not, but we must take care to ensure that the person properly understands the risk to self and others and is able to give this risk sufficient weight in making the decision. It is different where the person has committed a crime and there is a stronger case for public protection.

Northern Ireland's intention to have a single piece of legislation covering both incapacity and compulsory mental health treatment is bold and far-sighted. It may run into problems with children under the age of consent and with mentally disordered offenders if incapacity is a prerequisite for all forms of compulsion. Legislators must also be mindful of 'Bournewood gap' issues that have plagued incapacity law in other parts of the UK. England and Wales introduced the Deprivation of Liberty Safeguards to address them. In a forthcoming issue, Brindle $\&$ Branton (2010) comment on their complexity and the unclear interface with mental health legislation. In Scotland, social work legislation has been 'clarified' to allow for care provision, including place of residence, for the person without capacity where there is no deprivation of liberty and where neither the person nor others object; otherwise, guardianship or Mental Health Act measures must be sought.

\section{The right to refuse treatment}

The right to refuse treatment is fundamental. We all have a right to refuse to accept any measure that someone else thinks will be in our best interests. We may do this for good logical reasons or for no reason other than our emotional responses to the issues. Without accepting the existence of this right, all legislation becomes meaningless. We must only override such a refusal where a person's mental disorder interferes with the right to refuse and/or where the person does not appreciate the significance of the risk of refusal.

Nowhere is this more problematic than in the area of advance statements (Gavrilovic 2010). In England and Wales, advance refusals of treatment can be binding under the Mental Capacity Act. Under the Mental Health Act they are binding only for electroconvulsive therapy. For other treatments, they can be overridden. In Scotland, incapacity legislation does not specifically deal with advance statements except under the principle of taking account of past wishes. They are not binding. Under Scottish mental health legislation, people can make advance statements about how they would and would not wish to be treated. Any measure that conflicts with such a statement must be reported in writing to the Mental Welfare Commission. No treatment is exempt from an override of an advance refusal.

In my opinion, a properly and competently made advance statement should be obeyed. The clinical dilemma is determining what is 'proper and competent', whether it was made with an understanding of the consequences and whether the person foresaw the situation that now applies. Grey areas will remain and it may be that case law develops this area further. 


\section{Compulsory community treatment}

Community treatment (Brookes 2010; MacPherson 2010) should hold no fears if the Scottish experience is replicated elsewhere. Data published by the Mental Welfare Commission for Scotland (2009) show that, following the introduction of compulsory community treatment in 2005, the total number of people subject to long-term compulsion has not gone up. Around a third of people are now treated in the community instead of in hospital. Treatment appears generally appropriate and in line with the principle of least restriction of freedom. In England and Wales, the requirement that the person must first be detained under long-term provisions in hospital appear inconsistent with this principle.

\section{Conclusions}

Legislation varies in purpose, tone and content across the UK. Yet, when I chaired a session on incapacity at a recent meeting of the Royal College of Psychiatrists' Celtic Divisions, the similarity in philosophy and principle-based practice among all psychiatrists was striking. As a profession, we must stand by a set of principles and use them to interpret how best to apply the law wherever in the UK we happen to be practising. Benefit, least restriction of freedom and a culture of 'doing things with' rather than 'doing things to' our patients must pervade our clinical practice. Legislation should, in my view, be firmly rooted in such principles, detailed in primary legislation, not in a code of practice. Other jurisdictions can learn at least this much from Scotland.

\section{References}

Bamford Review of Mental Health and Learning Disability (Northern Ireland) (2007) A Comprehensive Legal Framework for Mental Health and Learning Disability. RMHLDNI (http://www.rmhldni.gov.uk/legalissue-comprehensive-framework.pdf)

Branton T, Brookes G (2010) Definitions and criteria: the 2007 amendments to the Mental Health Act 1983. Advances in Psychiatric Treatment 16: 161-167.

Brindle N. Branton T (2010) Interface between the Mental Health Act 1983 and the Mental Capacity Act: the Deprivation of Liberty Safeguards. Advances in Psychiatric Treatment 16: in press.

Brookes G, Brindle N (2010) Compulsion in the community? The introduction of supervised community treatment. Advances in Psychiatric Treatment 16: in press

Gavrilovic JJ, Richards F, Priebe S (2010) Advance statements in adult mental health. Advances in Psychiatric Treatment 16: in press.

MacPherson R (2010) Supervised community treatment: guidance for clinicians. Advances in Psychiatric Treatment 16: in press.

Mental Welfare Commission for Scotland (2009) Annual Monitoring: Overview 2008-2009. Total number of orders in existence. MWC (http:// reports.mwcscot.org.uk/annual_monitoring/overview2008-2009/total numbersofordersinexistence/total_number_of_orders_in_existence_09. aspx).

Ministry of Justice (2008) The Mental Capacity Act 2005: Deprivation of Liberty Safeguards. Code of Practice to Supplement the Main Mental Capacity Act 2005 Code of Practice. TSO (The Stationery Office) (http:// www.dh.gov.uk/prod_consum_dh/groups/dh_digitalassets/@dh/@en/ documents/digitalasset/dh_087309.pdf).

Salize, HJ, Dressing, H (2004) Epidemiology of involuntary placement of mentally ill people across the European Union. British Journal of Psychiatry 184: 163-8.

Sen P, Irons A (2010) Personality disorder and the new Mental Health Act. Advances in Psychiatric Treatment 16: in press. 